\title{
Chronic Exposure to Tumor Necrosis Factor (TNF) In Vitro Impairs the Activation of T Cells through the T Cell Receptor/CD3 Complex; Reversal In Vivo by Anti-TNF Antibodies in Patients with Rheumatoid Arthritis
}

\author{
Andrew P. Cope, Marco Londei, N. Randall Chu, Shara B. A. Cohen, Michael J. Elliott, Fionula M. Brennan, \\ Ravinder N. Maini, and Marc Feldmann \\ The Mathilda and Terence Kennedy Institute of Rheumatology, Sunley Division, Hammersmith, London, W6 8LW, United Kingdom
}

\begin{abstract}
Experiments were designed to test the hypothesis that chronic exposure to tumor necrosis factor alpha (TNF) alters the function of activated $T$ lymphocytes. Pretreatment of tetanus toxoid-specific $T$ cell clones with TNF for up to $16 \mathrm{~d}$ impaired rechallenge proliferative responses to antigen in a dose- and time-dependent fashion. IL-2 and PHA responses were preserved. Prolonged treatment with TNF impaired production of $\mathrm{IL-2}, \mathrm{IL-10}$, IFN $\gamma$, TNF, and lymphotoxin (LT) following stimulation with immobilized OKT3, and resulted in suboptimal expression of the $I L-2 R$ alpha chain (Tac) but not CD3, CD4, or HLA-DR antigens, when compared to untreated control cells. By contrast, pretreatment of $\mathbf{T}$ cells for prolonged periods in vitro with neutralizing anti-TNF monoclonal antibodies (mAb) enhanced proliferative responses, increased lymphokine production, and upregulated Tac expression following stimulation with OKT3. To determine whether TNF exerts immunosuppressive effects on $T$ cells in vivo, we studied cell-mediated immunity in patients with active rheumatoid arthritis (RA), before and after treatment with a chimeric anti-TNF mAb. Treatment with anti-TNF restored the diminished proliferative responses of $P B M C$ to mitogens and recall antigens towards normal in all patients tested. These data demonstrate that persistent expression of TNF in vitro and in vivo impairs cell-mediated immune responses. (J. Clin. Invest. 1994. 94:749-760.) Key words: tumor necrosis factor $\bullet T$ lymphocytes • immunosuppression • cell-mediated immunity - rheumatoid arthritis
\end{abstract}

\section{Introduction}

The short-term effects of the cytokine tumor necrosis factor alpha (TNF) ${ }^{1}$ have been studied extensively in vitro. A detailed

Address correspondence to Dr. Andrew P. Cope, Department of Microbiology and Immunology, Room D345, Sherman Fairchild Science Building, Stanford University School of Medicine, Stanford, CA 943055402.

Received for publication 5 January 1994 and in revised form 18 April 1994.

1. Abbreviations used in this paper: IDA, index of disease activity; LT, lymphotoxin; PE, phycoerythrin; PPD, purified protein derivative; SkSd, Streptokinase/Streptodornase; Tac, Tac antigen (1L-2R alpha chain); TNF-R, tumor necrosis factor receptor.

J. Clin. Invest.

(c) The American Society for Clinical Investigation, Inc.

0021-9738/94/08/0749/12 \$2.00

Volume 94, August 1994, 749-760 analysis reveals a pattern of responses that are considered immunostimulatory or proinflammatory (reviewed in reference 1). For example, TNF is a growth factor for T and B cells $(2,3)$, a potent activator of macrophages (4), and induces the production of proinflammatory mediators such as prostaglandins and collagenase (5) and other cytokines such as interleukin-1 (IL1) $(6,7)$, IL-6 (8), and granulocyte-macrophage colony stimulating factor (GM-CSF) by both hemopoetic and nonhemopoeitic cells $(9,10)$. During acute inflammatory responses these proinflammatory effects may be amplified further by TNF through upregulation of adhesion molecules intracellular adhesion molecule-1, vascular cell adhesion molecule-1, and endothelial leukocyte adhesion molecule- 1 on endothelium (11), and by the induction of chemoattractants such as IL-8 (12), thereby facilitating the trafficking of cells to sites of inflammation.

The long-term effects of TNF in disease, on the other hand, have been more difficult to define. Some clues have been provided by clinical studies of chronic inflammatory disease such as rheumatoid arthritis (RA), multiple sclerosis (13), and Crohn's disease (14), and chronic infections such as malaria (15), tuberculosis, and leishmaniasis (16), in which TNF expression is augmented. For example, one clinical manifestation thought to be related to chronic TNF exposure in vivo is the wasting syndrome known as cachexia, particularly characteristic of chronic parasitic infestation and malignancy $(1,17)$, but also a recognized feature of many chronic inflammatory diseases (18). There are other features of these conditions, such as immune dysfunction, which could also be due to sustained overproduction of cytokines, but which have not been investigated in any detail at the cellular level. Thus, detailed study of the long-term effects of TNF on cells present at sites of inflammation would be of interest, and might enhance our understanding of the cellular and molecular mechanisms that contribute to the pathogenesis of chronic inflammatory disease.

RA is a chronic inflammatory disease in which local, sustained overproduction of cytokines such as IL-1, IL-6, IL-8, GM-CSF, and TNF has been reported (19). Synovial cells, chiefly comprising monocytes and activated $T$ cells, with fewer fibroblasts, produce TNF spontaneously in culture $(20,21)$. In addition, they express high levels of TNF receptors (TNF-R) which are sustained for many days in culture, in contrast to the transient expression of some cytokine receptors (e.g., IL-2R, as well as TNF-R) observed on PHA and IL-2 stimulated peripheral blood mononuclear cells (PBMC) (22). These abnormal cytokine responses, and the notable reduction of inflammatory mediators by neutralizing TNF in RA synovial cultures (23, 24), have implicated TNF in the pathogenesis of RA (19-24). The development of a spontaneous arthritis in mice expressing a human TNF transgene modified by exchanging the $3^{\prime}$ untranslated region with that of human $\beta$-globin suggests further that persistent overexpression of TNF alone is sufficient to induce 
and perpetuate arthritis (25). This concept has also been supported by animal models of human RA such as collagen-induced arthritis in DBA/1 mice, in which anti-TNF antibody even when administered after the onset of arthritis ameliorates synovial hyperplasia and joint destruction (26). More recently, in an open phase I/II study, significant clinical benefit has been observed in RA patients receiving treatment with a neutralizing chimeric monoclonal antibody to TNF, cA2 (27). This important finding confirms that augmented expression of TNF persists in vivo for prolonged periods in rheumatoid patients and contributes to the processes that lead to active disease.

$\mathrm{T}$ lymphocytes are the predominant cell type in chronic rheumatoid synovial infiltrates (28). They express activation antigens such as VLA-4, LFA-1, class II major histocompatibility (MHC) molecules, and to a lesser extent IL-2R $(29,30)$. Since bioactive TNF is detectable in synovial joint cell cultures, as well as in synovial fluid (21), it is likely that synovial joint T cells overexpressing TNF-R are persistently exposed to TNF in vivo. These characteristics are similar to $\mathrm{T}$ cell lines or clones, which, when cultured in vitro for prolonged periods, are chronically activated, secrete abundant TNF (31), and express high levels of TNF-R (32, and A. Cope, unpublished data). Therefore, we decided to study cultures of antigen-specific $T$ cell clones derived from normal individuals as a model system for investigating the long-term effects of TNF in vitro. Our data suggest that chronic exposure to bioactive TNF in vivo could account for some of the abnormal features of $T$ cells derived from RA patients, such as impaired antigen and mitogen responses, and suppressed lymphokine production $(33,34,35)$. Furthermore, studies of cell-mediated immune responses in RA patients before and after treatment with anti-TNF have confirmed our in vitro observations, demonstrating that TNF exerts suppressive effects on cellular responses in vivo.

\section{Methods}

$T$ cells and cell culture conditions. All T cells were cultured in RPMI 1640 (Gibco, Paisley, Scotland), supplemented with $10 \%$ heat inactivated $\mathrm{AB}$ normal human serum, $2 \mathrm{mM}$ L-glutamine, $25 \mathrm{mM}$ Hepes, antibiotics, and $20 \mathrm{ng} / \mathrm{ml}$ purified recombinant human IL-2 (HoffmannLa Roche, Nutley, NJ), (complete medium, endotoxin $<50 \mathrm{pg} / \mathrm{ml}$ by the limulus amebocyte assay). Four tetanus toxoid-specific $\mathrm{T}$ cell clones were generated from antigen-reactive $T$ cell lines derived from the peripheral blood of two normal healthy individuals as previously described (36). Briefly, peripheral blood mononuclear cells (PBMC) were obtained by density centrifugation of heparinized whole blood over Ficoll/hypaque (source specific density $1.077 \mathrm{~g} / \mathrm{ml}$ ). Tetanus toxoid-specific $\mathrm{T}$ cell lines were derived by culturing PBMC for $7 \mathrm{~d}$ at a density of $10^{6}$ cells/ml in the presence of optimal concentrations (1/100 dilution) of tetanus toxoid (Wellcome Reagent Ltd., Beckenham, England; dialyzed against RPMI 1640 containing antibiotics), followed by a further 7-d culture in fresh complete medium. Cloning of $\mathrm{T}$ cell lines was by limiting dilution in Terasaki plates at a density of $0.3 \mathrm{cells} / \mathrm{well}$, in the presence of $4 \times 10^{4}$ irradiated ( $4000 \mathrm{rad} ; 1 \mathrm{rad}=0.01 \mathrm{~Gy}$ ) autologous or HLA-DR matched PBMC, tetanus toxoid (1/100), and IL-2 (20 ng/ $\mathrm{ml}$ ) for 5 to $7 \mathrm{~d}$. Expanding clones were propagated in complete medium for a further 5 to $7 \mathrm{~d}$ before a second round of stimulation with antigen and antigen-presenting cells. Subsequent stimulations were performed every 12 to $16 \mathrm{~d}$ in 24-well culture trays with alternate rounds of antigen or $1 \mu \mathrm{g} / \mathrm{ml}$ PHA (Difco Laboratories Inc., Detroit, MI) using equal numbers of $\mathrm{T}$ cells and irradiated PBMC as feeder cells. Fresh complete medium, containing IL-2 was added every 4-5 d. Antigen specificity was confirmed in 3-d proliferation assays (see below).

Central to our experiments was the method by which $\mathrm{T}$ cells were cultured with exogenous TNF. For each round of stimulation with antigen or mitogen plus irradiated PBMC, cells were cultured in complete medium in the presence or absence of $0.01-100 \mathrm{ng} / \mathrm{ml}$ TNF. Unless otherwise stated, cells were subsequently propagated with fresh complete medium, with further additions of TNF, approximately every $4 \mathrm{~d}$. Indomethacin (Sigma Chemical Co., St. Louis, MO), was used as indicated, at a final concentration of $10^{-5} \mathrm{M}$. At the end of each stimulation cycle, cells were washed thoroughly before resuspending in fresh medium. Cells were then studied for proliferative response (hereafter termed rechallenge or recall responses), expression of cell surface antigens, or for cytokine production, in the absence of TNF. The data presented, therefore, represent a comparison of the functions and phenotype of $\mathrm{T}$ cells cultured in the presence or absence of exogenous TNF for prolonged periods (up to $16 \mathrm{~d}$ ).

Proliferation assays. Unless otherwise stated, proliferation of antigen-specific $\mathrm{T}$ cell clones was determined by incorporation of $0.5 \mu \mathrm{Ci}$ $\left[{ }^{3} \mathrm{H}\right]$ thymidine (1 $\mathrm{Ci}=37 \mathrm{GBq}$ ) (Amersham Intl., Buckinghamshire, England) for the last 16 to $18 \mathrm{~h}$ of $72 \mathrm{~h}$ assays. In 96-well round bottomed trays, at a final volume of $200 \mu \mathrm{l}$, T cells $\left(2 \times 10^{4}\right)$ were added to fresh irradiated autologous or HLA-DR compatible PBMC feeder cells $\left(4 \times 10^{4}\right)$ in the presence of medium alone, IL-2 $(20 \mathrm{ng} /$ $\mathrm{ml}), 1 / 100$ dilution of tetanus toxoid, or $10 \mu \mathrm{g} / \mathrm{ml}$ Streptokinase/Streptodornase (SkSd; Lederle Laboratories, Gosport, UK) as a control antigen. Alternatively, the same proportions of $T$ cells and irradiated feeder cells were incubated with increasing concentrations of PHA. To evaluate proliferative responses to IL-2 or immobilized OKT3, $10^{5} \mathrm{~T}$ cells/well were added to flat bottomed 96-well trays in the presence of increasing concentrations of $\mathrm{IL}-2$, or to wells previously coated overnight with varying concentrations of affinity purified OKT3. After $72 \mathrm{~h}$ of culture, $\left[{ }^{3} \mathrm{H}\right]$ thymidine incorporation was assessed by harvesting cells onto glass fiber filters with a semiautomated cell harvester (Titertek 550; Flow Laboratories, Irvine, Ayrshire, Scotland) and counting in a liquid scintillation spectrometer (1219 rack $\beta$; LKB Instruments Inc., Bromma, Sweden). Results were expressed as arithmetic mean counts per minute (cpm) of triplicate cultures \pm SEM. For comparisons of multiple pretreatments, proliferative responses to antigen were expressed as a stimulation index by calculating the ratio of cpm obtained from each tetanus-specific response to the cpm obtained in the presence of $\mathrm{T}$ cells, antigen presenting cells, and medium alone.

Cytokines and antibodies. Recombinant human TNF $\alpha$ (specific activity $5.6 \times 10^{7} \mathrm{U} / \mathrm{mg}$, endotoxin content $<2 \mathrm{EU} / \mathrm{mg}$ ) was the gift of Dr. H. M. Shepard (Genentech Inc., San Francisco, CA). TNF was neutralized with $\mathrm{cA} 2$, a chimeric human/murine monoclonal antibody (Centocor Inc, Malvern, PA), consisting of the constant regions of human IgGl $\kappa$, coupled to the $\mathrm{Fv}$ region of a high-affinity neutralizing murine anti-human TNF $\alpha$ antibody. cA2 was sterile filtered, and used at $10 \mu \mathrm{g} / \mathrm{ml}$, a concentration calculated to inhibit the cytotoxicity of approximately $200 \mathrm{ng} / \mathrm{ml} \mathrm{TNF}$ by $50 \%$, on the basis of the human KYM 1D4 cell cytotoxicity assay (Butler et al., submitted).

Immunophenotyping of $T$ cells. To evaluate the expression of surface receptors and $\mathrm{T}$ cell activation markers under different culture conditions, cells were harvested at the indicated times, and washed twice in ice-cold wash buffer (PBS, $2 \%$ FCS, and $0.02 \%$ sodium azide). Where stated, cells were resuspended in $0.01 \mathrm{M}$ sodium citrate buffer ( $\mathrm{pH} 4.0$ ) at $4^{\circ} \mathrm{C}$ for $5 \mathrm{~min}$ to remove excess TNF bound to receptors, or residual OKT3 bound to $\mathrm{T}$ cells. Cells were then washed twice before incubating $2-5 \times 10^{5}$ cells with saturating concentrations of relevant antibody. All subsequent incubations were maintained at $4^{\circ} \mathrm{C}$. Antibodies used in this study were; Leu-4 (anti-CD3 conjugated to fluorescein isothiocyanate; Becton Dickinson, Cowley, UK); Leu-3a (anti-CD4 conjugated to phycoerythrin; Becton Dickinson; anti-Tac (anti-IL-2R $\alpha$ chain), Dr. T. Waldmann, National Institutes of Health, Bethesda, MD; anti-HLA-DR (conjugated to phycoerythrin, PE; Becton Dickinson); OX-20, specific for rat Ig kappa chain (Dr. D. Mason, Oxford University, UK) used as an isotype matched control antibody where relevant. The fluorescent signal of cells incubated with unconjugated antibodies was obtained with goat anti-mouse IgG-PE (Southern Biotechnology Associates, Birmingham, AL). Cells were washed further, fixed in $1 \%$ formaldehyde 
in PBS, and analyzed on a FACScan flow cytometer (Becton Dickinson). Viable stained cells $\left(10^{4}\right)$ were assessed for positive fluorescence by gating on forward and side scatter.

Cytokine assays. Cells pretreated with complete medium alone, TNF, or anti-TNF were harvested at the end of each cycle of stimulation, washed extensively, and resuspended at a density of $10^{6} \mathrm{cells} / \mathrm{ml}$ in fresh medium alone, in the absence of TNF or anti-TNF. $1 \mathrm{ml}$ of $\mathrm{T}$ cell suspension derived from each pretreatment was added in triplicate to 24-well culture trays previously coated with OKT3 (optimum coating concentration, $10 \mu \mathrm{g} / \mathrm{ml}$ ). Culture supernatants were harvested after 48 $\mathrm{h}$, sterile filtered and frozen at $-70^{\circ} \mathrm{C}$ until assayed. The lymphokines IL-4, IL-10, IFN $\gamma$, TNF, and lymphotoxin (LT) were measured by standard sandwich ELISA techniques using specific monoclonal and polyclonal antibodies, which were the generous gifts of Dr. F. Di Padova, Sandoz, Basel (IL-4), Dr. K. Moore, DNAX, Palo Alto, CA (IL10), Dr. D. Novick, The Weizmann Institute of Science, Rehovot, Israel (IFN $\gamma$ ), Dr. W. Buurman, University of Limburg, Netherlands (TNF), and Dr. A. Meager, National Institute of Biological Standards and Control, Herts, UK (LT). Detection polyclonal/monoclonal antibodies were biotinylated using a commercial kit (Amersham Intl.) according to the manufacturer's instructions, and the amount of detection antibody bound determined with a $1 / 2000$ dilution of streptavidin-horseradish peroxidase conjugate (Amersham, Intl.), followed by incubation with $o$-phenylenediamine dihydrochloride substrate (Sigma Chemical Co.). The enzymatic reaction was stopped with $2 \mathrm{~N} \mathrm{H}_{2} \mathrm{SO}_{4}$, and absorbance read at $490 \mathrm{nM}$. Quantification of cytokines was calculated using an Apple Macintosh computer software program (Assayzap) according to the absorbence obtained with varying concentrations of the relevant recombinant standard.

The presence of bioactive IL-2 in these culture supernatants was determined using the IL-2 dependent murine CT6 T cell line as described (37). Briefly, $48 \mathrm{~h}$ culture supernatants were harvested from $\mathrm{T}$ cells stimulated with immobilized OKT 3 in the presence of saturating concentrations of anti-Tac antibody, and added in twofold serial dilutions in triplicate to round bottomed 96-well culture trays containing $5 \times 10^{4}$ CT6 cells/well. Proliferation of CT6 cells was determined by incorporation of $\left[{ }^{3} \mathrm{H}\right]$ thymidine for the last $4 \mathrm{~h}$ of $24 \mathrm{~h}$ assays. Cells were harvested as described above. The amount of IL- 2 was determined from the cpm produced by a standard curve using recombinant human IL-2.

Proliferative responses of $P B M C$ from RA patients treated with $c A 2$. Six RA patients with longstanding active disease, and who fulfilled the revised 1988 American Rheumatism Association diagnostic criteria for rheumatoid arthritis, were studied (38). Details of these patients, all of whom had failed therapy with multiple disease modifying agents, are reported elsewhere (27). Heparinized whole blood was obtained from patients on day 0 , prior to commencing anti-TNF treatment $(10 \mathrm{mg} / \mathrm{kg}$ cA2, i.v.), on day 1 ( $24 \mathrm{~h}$ later), and at days 7 , or 28 as indicated. Patients received a second infusion of cA2 on day 14 . Clinical scores for each patient were assessed during anti-TNF treatment using a composite index of disease activity (IDA, range 1-4) (39). All PBMC were obtained by density centrifugation as described above and cryopreserved prior to study. Serial unfractionated PBMC samples from each patient were then studied at the same time (to avoid interassay variability) for their proliferative responses to a panel of mitogens and soluble antigens. Thawed PBMC from each time point were washed, counted, and resuspended at $10^{6} \mathrm{cells} / \mathrm{ml}$. To 96-well round-bottomed trays containing 100 $\mu \mathrm{l}$ of this cell suspension was added $100 \mu \mathrm{l}$ of either medium alone, or medium containing optimal concentrations of IL-2 $(20 \mathrm{ng} / \mathrm{ml})$, OKT3 $(50 \mathrm{ng} / \mathrm{ml})$, PHA $(4 \mu \mathrm{g} / \mathrm{ml})$, concanavalin A $(4 \mu \mathrm{g} / \mathrm{ml})$ (Sigma Chemical Co.), tetanus toxoid (1/100 dilution), tuberculin purified protein derivative (PPD, $10 \mu \mathrm{g} / \mathrm{ml}$; Evans, Horsham, UK), or SkSd $(5 \mu \mathrm{g} / \mathrm{ml})$, as determined in preliminary experiments. Cells incubated with IL-2 or mitogen, or with soluble antigens were harvested after 3 and $6 \mathrm{~d}$ of culture, respectively, following the addition of $0.5 \mu \mathrm{Ci}\left[{ }^{3} \mathrm{H}\right]$ thymidine for the last 16 to $18 \mathrm{~h}$ of culture, as described above. Results of proliferative responses from serial time points are expressed as counts per minute or as stimulation indices.

Statistical analysis. All statistical analyses were performed using
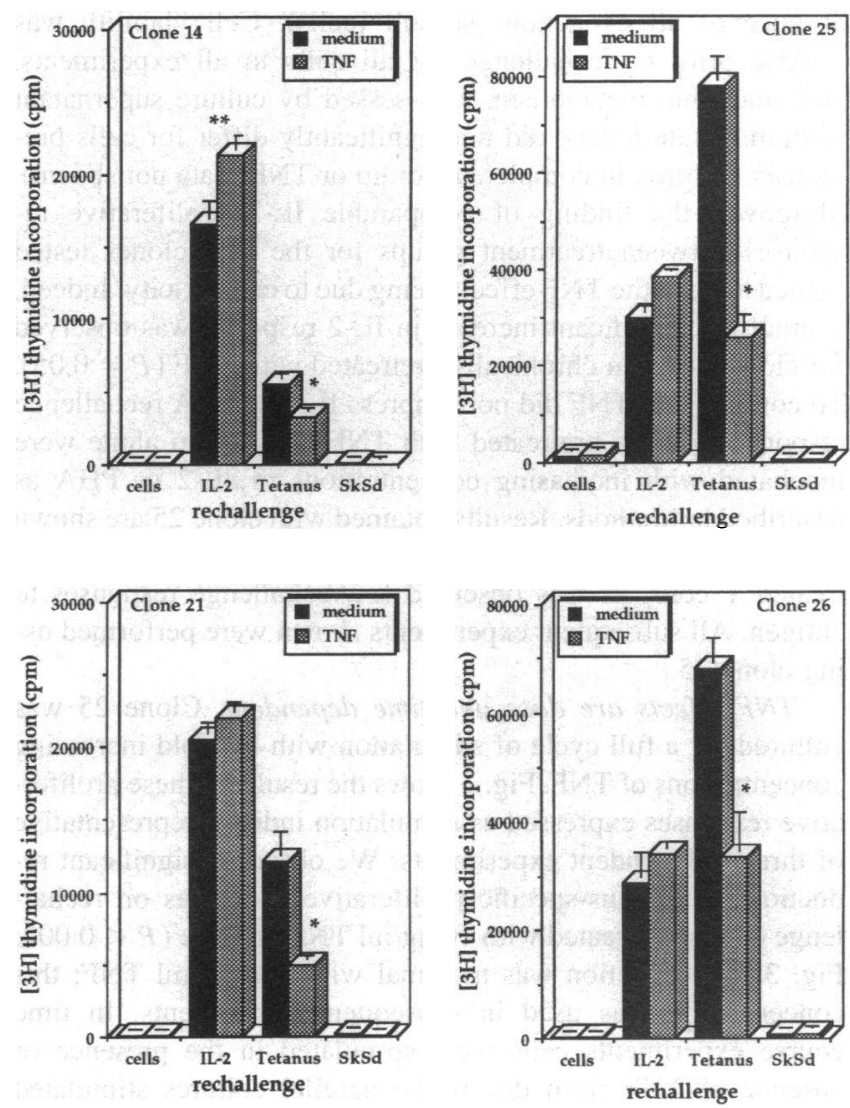

Figure 1. Prolonged exposure of $\mathrm{T}$ cell clones to TNF suppresses tetanus toxoid-specific recall responses. Four CD4+ T cell clones were independently stimulated with APC, tetanus toxoid, and IL-2 in the absence (medium) or presence of TNF $(100 \mathrm{ng} / \mathrm{ml})$ for 12 to $16 \mathrm{~d}$, before rechallenge with medium alone, IL-2 $(20 \mathrm{ng} / \mathrm{ml})$, tetanus toxoid $(1 / 100 \mathrm{dilu}-$ tion) or irrelevant control antigen (SkSd, $10 \mu \mathrm{g} / \mathrm{ml})$. Data represent mean cpm of triplicate cultures \pm SEM derived from the $\left[{ }^{3} \mathrm{H}\right]$ thymidine incorporated during the last $16-18 \mathrm{~h}$ of $72 \mathrm{~h}$ proliferation assays performed in the absence of exogenous TNF. Statistically significant differences between treatments are indicated $\left(* P<0.04 ;{ }^{* *} P=0.05\right)$.

the Apple Macintosh software statistics package, Minitab. Comparisons between proliferative responses (mean \pm SEM) and differences in lymphokine production (mean $\pm \mathrm{SD}$ ) were determined by nonpaired $t$ tests. The Wilcoxon signed rank test was used to compare stimulation indices between time points for RA patients as a group. Differences were considered statistically significant at $P<0.05$.

\section{Results}

Effects of prolonged TNF exposure on in vitro tetanus toxoid specific responses. Four tetanus specific $\mathrm{T}$ cell clones derived from two healthy donors were studied. For each clone, cells pretreated with TNF $(100 \mathrm{ng} / \mathrm{ml})$ showed significant reductions in tetanus specific proliferative responses compared to $\mathrm{T}$ cell clones cultured with complete medium alone $(P<0.05$, Fig. 1). This was a consistent and reproducible finding for all four clones tested. Thus, in 12 separate experiments the mean percent reduction in the tetanus specific stimulation index of TNF pretreated cells was $56 \pm 18 \%$ (mean \pm SD) for clone 25 . By comparison, thymidine incorporation in response to irrelevant antigen (SkSd) was similar to that observed for cells cultured in the 
absence of all exogenous stimuli (cells). Cell viability was $>95 \%$ prior to rechallenge for all cells in all experiments, and anaerobic metabolism, as assessed by culture supernatant sodium lactate levels, did not significantly differ for cells previously cultured in complete medium or TNF (data not shown). Moreover, the finding of comparable IL-2 proliferative responses between treatment groups for the four clones tested argued against the TNF effects being due to cell toxicity. Indeed, a small but significant increase in IL- 2 response was observed for clone 14 when chronically pretreated with TNF $(P=0.05)$. To confirm that TNF did not suppress IL-2 or PHA rechallenge responses, clones pretreated with TNF or medium alone were incubated with increasing concentrations of IL-2 or PHA as described in Methods. Results obtained with clone 25 are shown in Fig. 2. No reduction of proliferation was observed with TNF treated $\mathrm{T}$ cells, as was observed for rechallenge responses to antigen. All subsequent experiments shown were performed using clone 25.

TNF effects are dose and time dependent. Clone 25 was cultured for a full cycle of stimulation with log-fold increasing concentrations of TNF. Fig. 3 shows the results of these proliferative responses expressed as stimulation indices, representative of three independent experiments. We observed significant reductions in tetanus-specific proliferative responses on rechallenge of T cells treated with $10 \mathrm{ng} / \mathrm{ml} \mathrm{TNF}$ or more $(P<0.002$; Fig. $3 A$ ). Reduction was maximal with $100 \mathrm{ng} / \mathrm{ml}$ TNF; this concentration was used in subsequent experiments. In time course experiments cells were stimulated in the presence or absence of TNF from day 0 . To parallel cultures stimulated initially in the presence of complete medium, were added TNF $(100 \mathrm{ng} / \mathrm{ml})$ at subsequent, later time points as indicated. A reduction in tetanus rechallenge responses was observed as before for cell cultures in which TNF $(100 \mathrm{ng} / \mathrm{ml})$ was added every $4 \mathrm{~d}$ from day 0 . Similar significant reductions were noted when TNF was added from days 4,8 , or $12(P<0.002)$. However, less suppression was noted when TNF was added progressively later, and no reduction when added to cultures just $24 \mathrm{~h}$ prior to rechallenge with antigen (day 15). These data demonstrate that pretreatment of T cells with TNF suppressed antigen-specific rechallenge responses in both a dose- and timedependent fashion.

TNF effects are reversible, and independent of the initial stimulus and the presence of antigen-presenting cells. In order to characterize these TNF effects in more detail, we studied clone 25 cultured in the presence or absence of TNF under different culture conditions. These experiments (I-VI) are summarized in Table $I$; the percentage reduction of antigen specific responses by TNF is also shown for corresponding experiments. For each experiment clone 25 was stimulated under the conditions indicated in the presence or absence of exogenous TNF, before rechallenge with optimal concentrations of tetanus toxoid as described above. Experiment I demonstrates that recall proliferative responses were suppressed by pretreatment with TNF irrespective of whether antigen was processed and presented by PBMC from either of two different HLA-DR matched donors (Imo and TMc), or by a DR-matched EBV transformed B cell line (EBV). Suppression was also observed if cells were stimulated at the beginning of the cycle with either antigen or mitogen such as PHA, and then rechallenged with antigen and the same antigen presenting cells (experiment II). Furthermore, significant reductions in rechallenge responses were still observed in cells stimulated with immobilized OKT3 and IL-2 alone, and
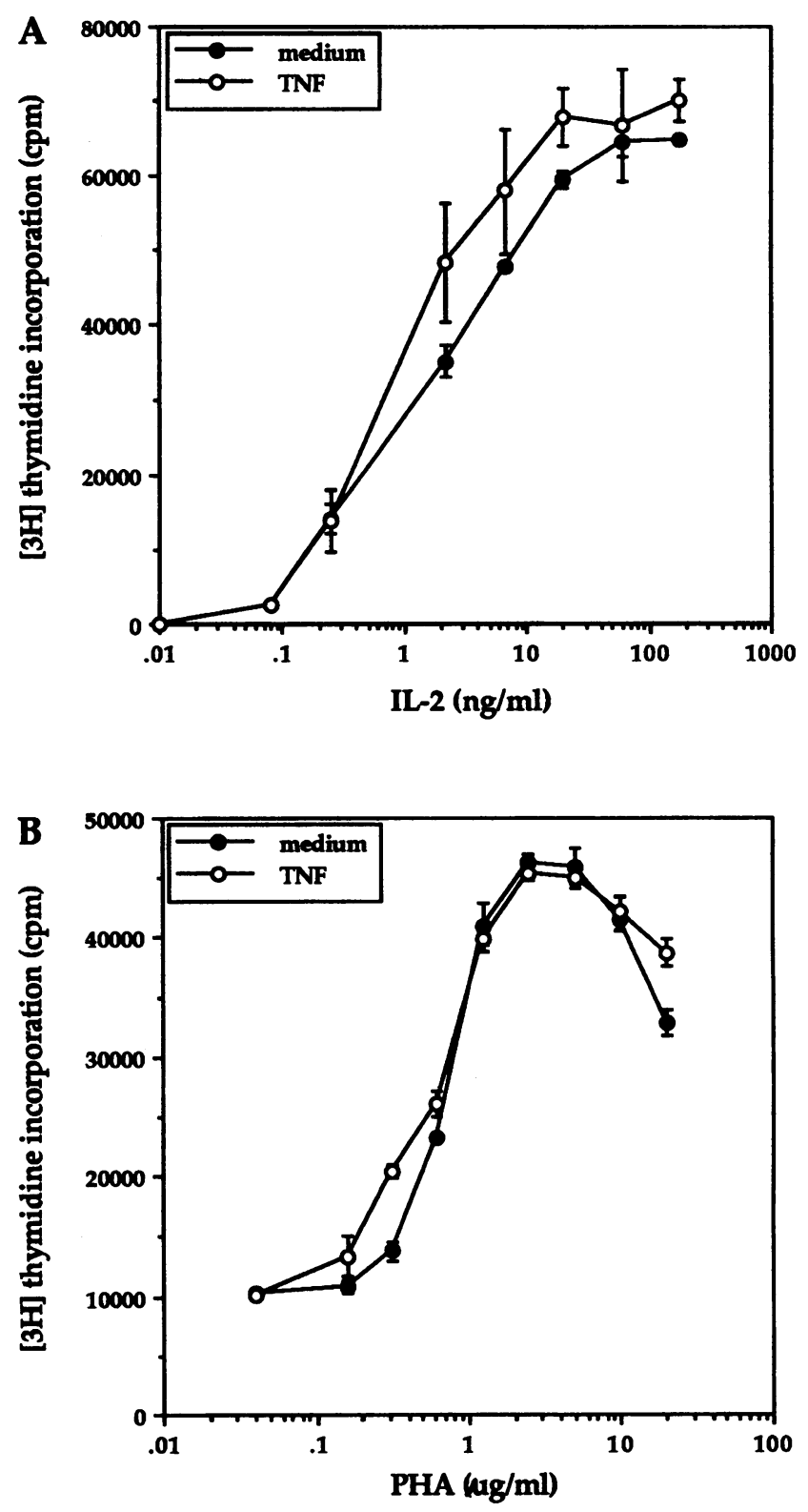

Figure 2. IL-2- and PHA-induced proliferative responses of T cells chronically treated with TNF are preserved. Clone 25 was stimulated as described for Fig. 1. Following pretreatment with or without TNF $(100 \mathrm{ng} / \mathrm{ml})$, proliferative responses to increasing concentrations of $A$ ) IL-2 alone or $B$ ) PHA (in the presence of APC) were evaluated. Each point represents mean cpm of triplicate cultures $\pm S E M$ in $72 \mathrm{~h}$ recall assays in the absence of exogenous TNF.

then rechallenged with antigen and PBMC as antigen presenting cells (Imo or TMc; experiment III). When T cells were rechallenged with antigen in the presence of HLA-DR-matched EBV transformed B cells, the differences in responses of untreated and TNF-treated cells were found to be smaller (as observed in experiment I), but differences still reached statistical significance $(P<0.05)$. These findings suggested that TNF induced these effects on $\mathrm{T}$ cells directly and independently of accessory cells and their products (experiment III). Experiment IV confirmed that similar results were obtained in the presence of cyclooxygenase inhibitors (indomethacin $10^{-5} \mathrm{M}$ ), implying 

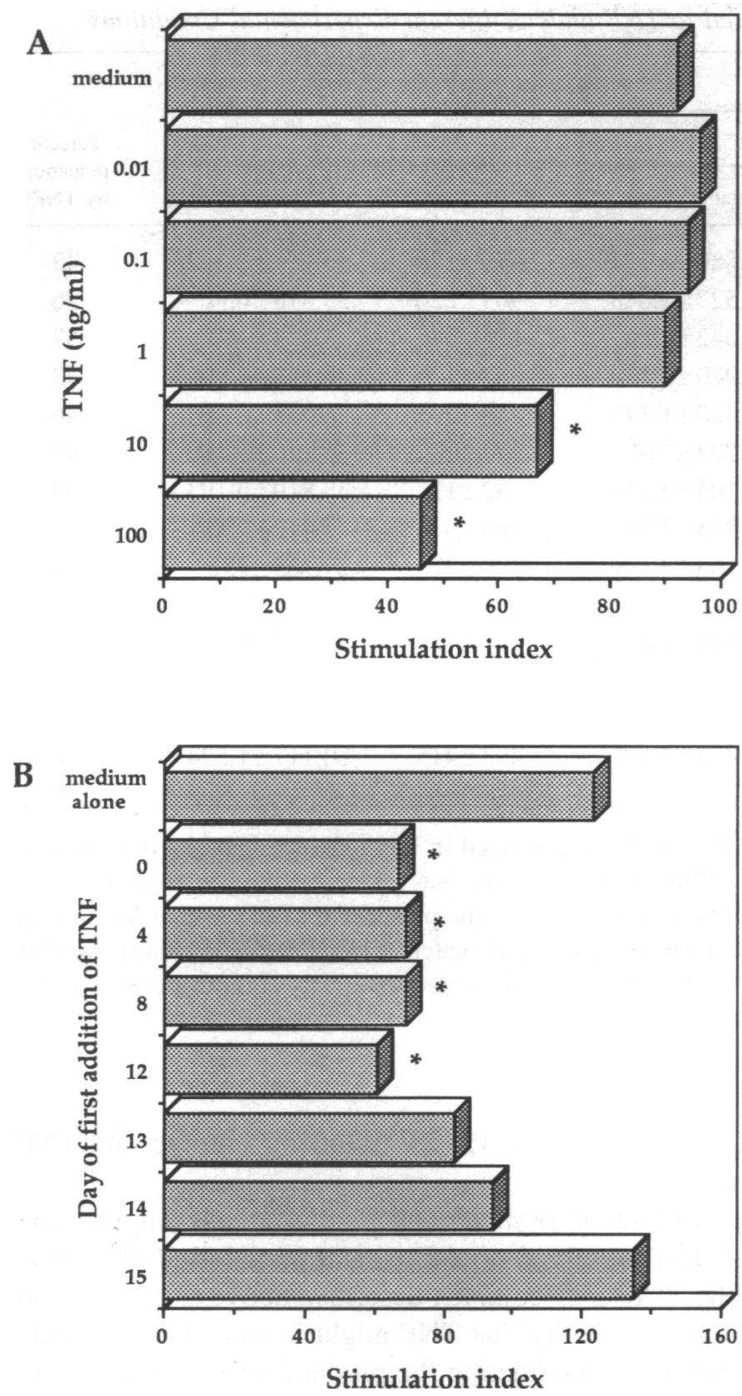

Figure 3. Chronic exposure of T cells to TNF impairs tetanus toxoidspecific recall responses in a dose- and time-dependent fashion. Clone 25 was stimulated as described for Fig. 1 in the presence or absence of increasing concentrations of TNF $(A)$ for $14 \mathrm{~d}$ prior to evaluating recall responses to antigen. For kinetic studies $(B)$, TNF $(100 \mathrm{ng} / \mathrm{ml})$ was added at the beginning of cultures, or on subsequent days, as indicated, to separate cultures that had been stimulated initially in the presence of complete medium. Further TNF was added every $4 \mathrm{~d}$ until day 12 . For those cultures to which TNF was added for the first time from days 12 to 15 , TNF was added only once. Cells were washed thoroughly before rechallenge with tetanus toxoid in the absence of exogenous TNF. Results are expressed as stimulation indices. Statistically significant differences are indicated $(* P<0.002)$.

that these suppressive effects were unlikely to result from the induction of arachidonic acid metabolites by TNF. If, at the end of the cycle, one wash was replaced by a 5-min incubation with ice-cold citrate buffer ( $\mathrm{pH} 4.0$ ) to displace residual TNF bound to surface receptors, suppressive effects could be reproduced, suggesting that the reduction in antigen-specific responses during rechallenge was unlikely to be due to a carryover effect of TNF (experiment V). Finally, to see if TNF effects were reversible, cells underwent two consecutive stimulation and rechallenge cycles (experiment VI). In the first, clone 25 was stimulated and cultured with and without TNF $(100 \mathrm{ng} / \mathrm{ml})$ as before.
In the second, both groups of cells underwent a stimulation cycle in the absence of exogenous TNF. Rechallenge after the first cycle showed significant reduction in tetanus specific responses. Following a full cycle of stimulation $(\sim 2 \mathrm{wk})$ in the absence of exogenous TNF, antigen specific responses of these cells in a second recall assay were comparable to control levels (reduction $\sim 1 \%$ ). Together these experiments-demonstrate that chronic exposure to TNF suppresses antigen-specific $\mathrm{T}$ cell responses irrespective of the type or presence of antigen-presenting cells, the initial stimulus, or the presence of prostaglandins. Furthermore, these effects are reversible in vitro, arguing against the likelihood of cytotoxic effects.

Endogenous TNF production has suppressive effects. T cell clones cultured in vitro are chronically activated and secrete abundant TNF (31). Since a reduction in antigen-specific responses occurred at TNF concentrations between 1 and $10 \mathrm{ng} /$ $\mathrm{ml}$, we reasoned that endogenous TNF produced spontaneously by $\mathrm{T}$ cell clones in culture could exert similar effects. Furthermore, it was possible that membrane-associated TNF expressed on these cells (data not shown) would also contribute to the levels of endogenous TNF bioactivity. Therefore we stimulated clone 25 (which produces TNF; see Table II) in the presence of neutralizing concentrations of the chimeric anti-TNF mAb $\mathrm{cA} 2$, and compared rechallenge responses with those obtained from cells pretreated with or without exogenous TNF. To avoid possible interference of the chimeric $\mathrm{cA} 2 \mathrm{mAb}$ binding to $\mathrm{Fc} \gamma$ receptors on antigen-presenting cells, we cultured $\mathrm{T}$ cells without accessory cells during both the stimulation cycle and the recall response, by using immobilized OKT3. Fig. 4 shows the results (representative of five experiments) of proliferative responses of cells pretreated with complete medium, TNF or anti-TNF to increasing concentrations of immobilized OKT3, harvested 3 (Fig. $4 \mathrm{~A}$ ) or $7 \mathrm{~d}$ after stimulation (Fig. $4 \mathrm{~B}$ ). While TNF reduced these responses, cells pretreated with anti-TNF demonstrated significantly enhanced proliferation $(P<0.05)$. Although significant differences were observed between treatments for all concentrations of OKT3, they were most marked at suboptimal concentrations. The differences in proliferation between the three pretreatments observed after $7 \mathrm{~d}$ of stimulation with OKT3, however, indicated that the cells had begun to recover, since the suppression or enhancement induced by TNF or anti-TNF, respectively, was less marked. These data suggested that the levels of endogenous TNF expressed in soluble and membrane form following stimulation of $\mathrm{T}$ cells are sufficient to exert suppressive effects.

Effects of TNF on expression of cell surface antigens. Significant reductions in OKT3 induced proliferation of TNF pretreated cells suggested the possibility of a perturbation of the IL-2/IL-2R system by chronic exposure of T cells to TNF. To address this, we evaluated cell surface Tac expression (IL-2R $\alpha$ chain) on cells pretreated with or without TNF, or with antiTNF, and compared these findings with the expression of CD3, CD4, and HLA-DR (Fig. 5). We observed several patterns of surface antigen expression with chronic TNF treatment. Thus, prior to OKT3 stimulation, the expression of Tac and HLA-DR were upregulated as reported previously $(32,40)$, while levels of CD3 and CD4 antigens did not change with TNF treatment. However, upon stimulation with immobilized OKT3, levels of Tac on untreated cells were dramatically increased, while levels on TNF pretreated cells changed little from prestimulation levels; upregulation of IL-2R was thus impaired. By contrast, there were no changes noted in the expression of CD3, CD4, or HLA- 


\begin{tabular}{|c|c|c|c|c|c|c|c|}
\hline \multirow{3}{*}{$\begin{array}{c}\begin{array}{c}\text { Experiment } \\
\text { no. }\end{array} \\
\end{array}$} & \multirow[b]{3}{*}{ Initial stimulation } & \multirow[b]{3}{*}{ Recall APC } & \multicolumn{4}{|c|}{ Pretreatment } & \multirow{3}{*}{$\begin{array}{l}\text { Percent } \\
\text { reduction } \\
\text { by TNF* }\end{array}$} \\
\hline & & & \multicolumn{2}{|c|}{ Untreated } & \multicolumn{2}{|c|}{ TNF } & \\
\hline & & & Cells alone & Tetanus toxoid & Cells alone & Tetanus toxoid & \\
\hline \multirow[t]{3}{*}{ I } & Antigen & $\mathrm{IMo}^{\ddagger}$ & $441 \pm 58^{8}$ & $40,880 \pm 2,123$ & $579 \pm 128$ & $23,111 \pm 2,142$ & 43 \\
\hline & Antigen & TMc & $568 \pm 150$ & $60,527 \pm 1,078$ & $903 \pm 220$ & $38,878 \pm 654$ & 36 \\
\hline & Antigen & EBV & $593 \pm 57$ & $8,042 \pm 495$ & $658 \pm 68$ & $3,474 \pm 163$ & 57 \\
\hline \multirow[t]{2}{*}{ II } & Antigen & IMo & $2,369 \pm 672$ & $50,970 \pm 3,136$ & $2,283 \pm 129$ & $28,542 \pm 1,992$ & 43 \\
\hline & Mitogen & IMo & $750 \pm 322$ & $48,420 \pm 1,176$ & $264 \pm 50$ & $25,932 \pm 614$ & 46 \\
\hline \multirow[t]{3}{*}{ III } & Immobilized OKT3 & IMo & $61 \pm 5$ & $63,702 \pm 719$ & $275 \pm 92$ & $36,236 \pm 1,680$ & 43 \\
\hline & Immobilized OKT3 & TMc & $171 \pm 65$ & $82,105 \pm 4,111$ & $82 \pm 12$ & $38,819 \pm 3,193$ & 53 \\
\hline & Immobilized OKT3 & EBV & $614 \pm 42$ & $3,825 \pm 320$ & $564 \pm 6$ & $2,412 \pm 290$ & 37 \\
\hline \multirow[t]{3}{*}{ IV } & Immobilized OKT3 & TMc & $105 \pm 1$ & $75,163 \pm 3,159$ & $170 \pm 27$ & $29,765 \pm 952$ & 60 \\
\hline & Immobilized OKT3 & & & & & & \\
\hline & + indomethacin & TMc & $194 \pm 80$ & $65,844 \pm 1,423$ & $175 \pm 45$ & $31,167 \pm 918$ & 53 \\
\hline $\mathbf{V}$ & Mitogen & TMc acid treatment & $508 \pm 110$ & $64,690 \pm 2,649$ & $935 \pm 257$ & $43,517 \pm 517$ & 33 \\
\hline \multirow[t]{2}{*}{ VI } & Antigen (1st cycle) & TMc & $569 \pm 150$ & $60,527 \pm 1,078$ & $903 \pm 220$ & $38,878 \pm 654$ & 36 \\
\hline & Antigen (2nd cycle) & TMc & $1,228 \pm 272$ & $81,342 \pm 3,502$ & $1,493 \pm 415$ & $80,117 \pm 1,524^{\|}$ & 1 \\
\hline
\end{tabular}

T cells were cultured for 12 to $16 \mathrm{~d}$ in the presence or absence (untreated) of TNF ( $100 \mathrm{ng} / \mathrm{ml}$ ), as described in Methods, washed and restimulated with antigen presenting cells (APC) and antigen for $72 \mathrm{~h}$ in the absence of exogenous TNF. $\left[{ }^{3} \mathrm{H}\right]$ Thymidine was added for the last 16 to $18 \mathrm{~h}$ of culture. *\% reduction by TNF calculated according to the equation $100-([\mathrm{cpm}$ for antigen response in the presence of TNF $\div \mathrm{cpm}$ for antigen response of untreated cultures] $\times 100) ;{ }^{\ddagger}$ APC used: IMo/TMc, DR matched irradiated PBMC; EBV, DR matched irradiated EBV transformed B cells; ${ }^{8}$ results are expressed as mean $\mathrm{cpm} \pm \mathrm{SEM}$. Differences between all untreated vs TNF treated cells were statistically significant $(P<0.05)$ unless indicated, " $P>0.1$; see test for explanation of Experiments I-VI.

DR. In separate experiments we found that the reverse was true for cells treated with anti-TNF (Fig. $5 \mathrm{~B}$ ), since Tac expression was further upregulated compared to untreated control cells following activation with OKT3. By comparison, levels of CD3, CD4, and HLA-DR on anti-TNF pretreated cells were unaltered (data not shown). These observations suggested that modulation of proliferative responses to OKT3 previously noted was unlikely to be due to direct effects on CD3 expression; likewise changes in CD4 or HLA-DR expression were considered unlikely to be the mechanisms for reductions in antigen-specific responses induced by chronic TNF treatment. By contrast, upregulation of Tac could have contributed to the increased proliferative responses to OKT3 following chronic anti-TNF treatment.

Effects of TNF pretreatment on lymphokine production. The effects of TNF observed on subsequent stimulation of T cells through the TCR/CD3 complex described above (Fig. 1, 4, and 5), raised the possibility that TNF might in someway modulate $\mathrm{T}$ cell function by modulating the production of $\mathrm{T}$ cell growth factors such as IL-2, or immunoregulatory cytokines such as IL10. We therefore compared the production of six lymphokines in $48 \mathrm{~h}$ culture supernatants of $\mathrm{T}$ cells cultured under normal conditions with those produced by $\mathrm{T}$ cells pretreated with TNF or anti-TNF. Table II shows the results representative of six

Table II. OKT3-Induced Cytokine Production by Clone 25

\begin{tabular}{|c|c|c|c|c|c|c|}
\hline \multirow[b]{2}{*}{ Treatment } & \multicolumn{6}{|c|}{ Lymphokine (pg/ml) } \\
\hline & IL-2 & $\mathbb{L}-4$ & $\mathrm{IFN} \gamma$ & IL-10 & LT & TNF \\
\hline \multicolumn{7}{|l|}{ Experiment 1} \\
\hline Medium & $596 \pm 20$ & $<40$ & $4,243 \pm 178$ & $<40$ & $4,214 \pm 273$ & $608 \pm 28$ \\
\hline TNF & $209 \pm 4$ & $<40$ & $3,144 \pm 37^{*}$ & $<40$ & $2,395 \pm 159$ & $497 \pm 60$ \\
\hline Anti-TNF & $974 \pm 31$ & $<40$ & $6,275 \pm 145$ & $251 \pm 7$ & $5,523 \pm 440$ & $1,075 \pm 192$ \\
\hline \multicolumn{7}{|l|}{ Experiment 2} \\
\hline Medium & $31 \pm 2$ & $<40$ & $2,883 \pm 16$ & $<40$ & $366 \pm 8$ & $213 \pm 29$ \\
\hline TNF & $5 \pm 2 *$ & $<40$ & $811 \pm 38$ & $<40$ & $<40$ & $<40$ \\
\hline Anti-TNF & $114 \pm 16$ & $<40$ & $5,278 \pm 99$ & $290 \pm 6$ & $2,461 \pm 203$ & $1,086 \pm 90$ \\
\hline
\end{tabular}

Cells were pretreated with medium alone, TNF $(100 \mathrm{ng} / \mathrm{ml})$ or anti-TNF $(10 \mu \mathrm{g} / \mathrm{ml})$ as described for Fig. 4 . Cytokines were measured by ELISA, except for IL-2 which was assayed using the IL-2 dependent murine T cell line CT6. Culture supernatants were harvested $48 \mathrm{~h}$ after stimulation with optimal concentrations of immobilized OKT3. Where detectable, differences in lymphokine production between all treatment groups were statistically significant $(P<0.005)$, unless otherwise indicated, $\quad * P<0.05$. 

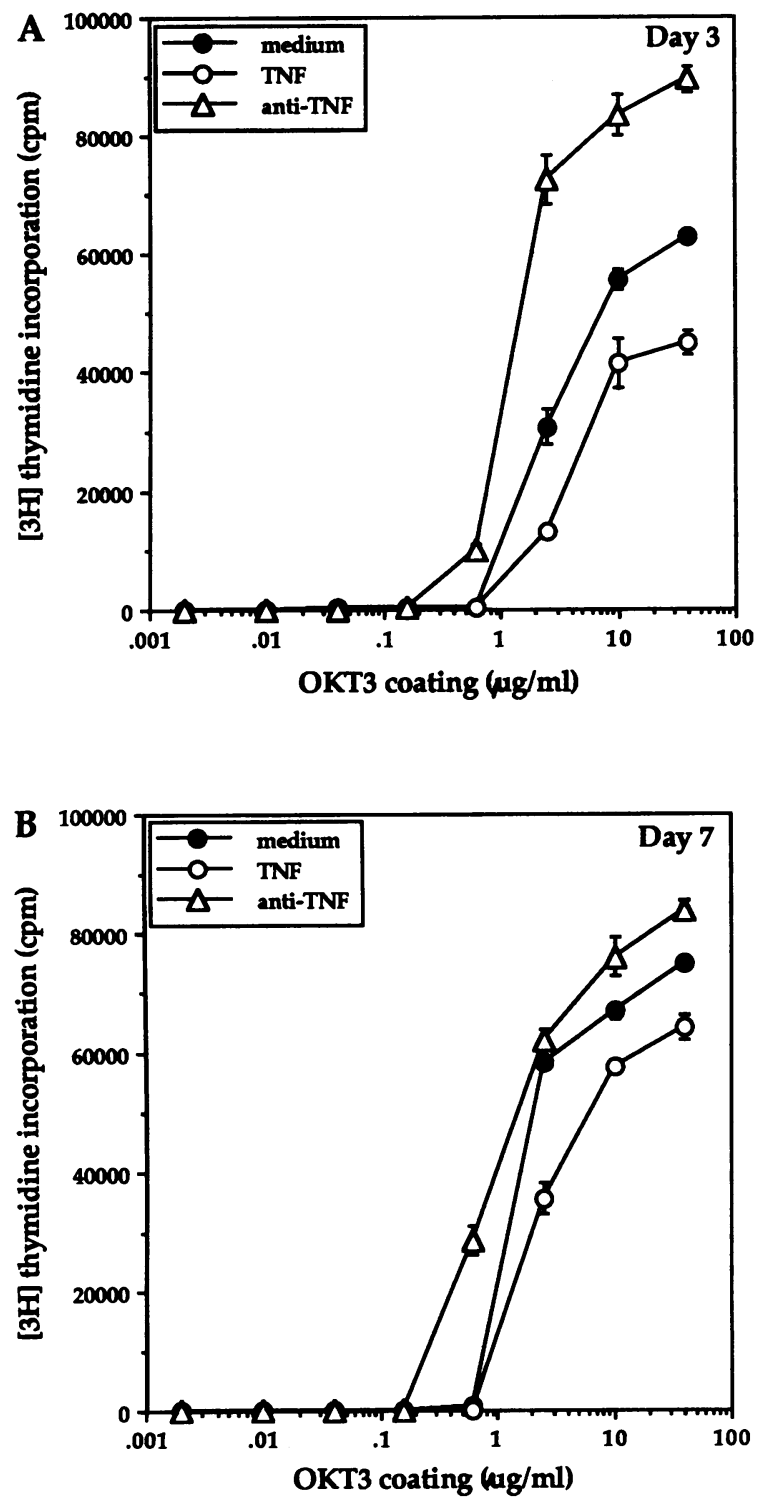

Figure 4. Effects of pretreatment of $\mathrm{T}$ cells with TNF or anti-TNF mAb on OKT3-induced proliferation. Clone 25 was stimulated with immobilized OKT3 and IL-2 for 14 to $16 \mathrm{~d}$ in the presence of complete medium alone, TNF $(100 \mathrm{ng} / \mathrm{ml})$ or anti-TNF $(10 \mu \mathrm{g} / \mathrm{ml})$, prior to washing and restimulating with increasing concentrations of immobilized OKT3 for $3 \mathrm{~d}(A)$ or $7 \mathrm{~d}(B)$ in the absence of exogenous TNF or anti-TNF. Each point represents mean of triplicate cultures \pm SEM.

experiments. Evaluation of the cytokine profile of cells cultured under normal conditions revealed abundant production of IFN $\gamma$ with lower amounts of IL-2, LT, and TNF. Neither IL-4 nor IL-10, cytokines with potential anti-inflammatory effects, could be detected. Interestingly, there were highly significant reductions in the levels of nearly all cytokines detected in culture supernatants of stimulated cells previously treated with TNF ( $P$ $<0.005$ ). More surprising was the finding that cells pretreated with anti-TNF produced higher levels of cytokines than cells pretreated with or without TNF. Significantly, anti-TNF restored lymphokine production, as shown in the case of IL-10 for both experiments, and for LT and TNF in experiment 2; IL-4 was not detected in any of the culture supernatants tested. The ab- sence of TNF production by TNF-treated cells shown in experiment 2 , was further evidence against possible carry-over effects of high concentrations of TNF. We have also been able to demonstrate that, like antigen-specific responses (Fig. 3), chronic TNF exposure impaired the production of lymphokines such as IFN $\gamma$ in a dose- and time-dependent fashion (data not shown). These data are consistent with the proliferative responses to immobilized OKT3, in as much as TNF pretreatment suppressed, while anti-TNF pretreatment enhanced $\mathrm{T}$ cell responses.

Effects of cA2 treatment on proliferative responses of $P B M C$ from patients with $R A$. To assess whether prolonged exposure to TNF also altered cellular immune responses in vivo, we studied mitogen and soluble recall antigen proliferative responses of PBMC obtained from RA patients with longstanding active disease who had received intravenous therapy with a chimeric anti-TNF mAb in an open phase I/II clinical trial (27). The results from patient 17 , expressed as cpm, are illustrated in Fig. 6, and the data from all six patients are summarized in Table III. For patient 17, proliferative responses were evaluated before treatment and on days 7 and 28 after anti-TNF therapy. Responses to all mitogens and recall antigens except PHA, were markedly impaired before treatment. Within $7 \mathrm{~d}$, increases in all mitogen responses were observed, including those to $\mathrm{IL}-2$, while an increase in PPD response was also noted. By day 28, further significant increases were noted for all mitogens and antigens $(P<0.03)$, including tetanus toxoid, to which responses were lower than those to PPD and SkSd. Similar patterns were observed over this time period when responses to suboptimal concentrations of mitogen and antigen were tested (see Table III). Table III compares the stimulation indices to the clinical scores of each patient, assessed during treatment using a composite index of disease activity (IDA) score. Apart from the IL-2 and PHA responses in patient 19, all stimulation indices increased after commencing anti-TNF treatment. Furthermore, concomitant improvements in clinical scores (as indicated by a fall in IDA) were observed. For example, sustained improvement in both clinical and stimulation indices were noted for patient 17 throughout the 28-d test period. Even greater improvements in stimulation indices and IDA were observed for patient 20 within $7 \mathrm{~d}$ of commencing cA2 therapy, although the effects appeared more transient, since both indices fell by day 21 . Nevertheless, both clinical and cellular responses at day 21 were still increased above those observed on day 0 . Responses to tetanus toxoid precluded statistical analysis, while the remaining responses revealed significant differences between pretreatment and peak stimulation indices posttherapy for IL-2, OKT3, Con A, PPD, and SkSd $(P<0.04)$, but not PHA $(P>0.05)$.

\section{Discussion}

A detailed knowledge of the short-term effects of TNF on cells cultured in vitro has enhanced our understanding of the role of TNF in pathophysiology (1). Much of the data reported to date have addressed the mechanisms by which TNF contributes to the inflammatory response through its effects on monocytes and macrophages. These cells constitutively express TNF-R (41) and stimulation with TNF induces cell activation, enhancement of phagocytic activity, and induction of the respiratory burst (4), biological processes of particular importance in host defense. Resting $\mathrm{T}$ lymphocytes, on the other hand, express very low 


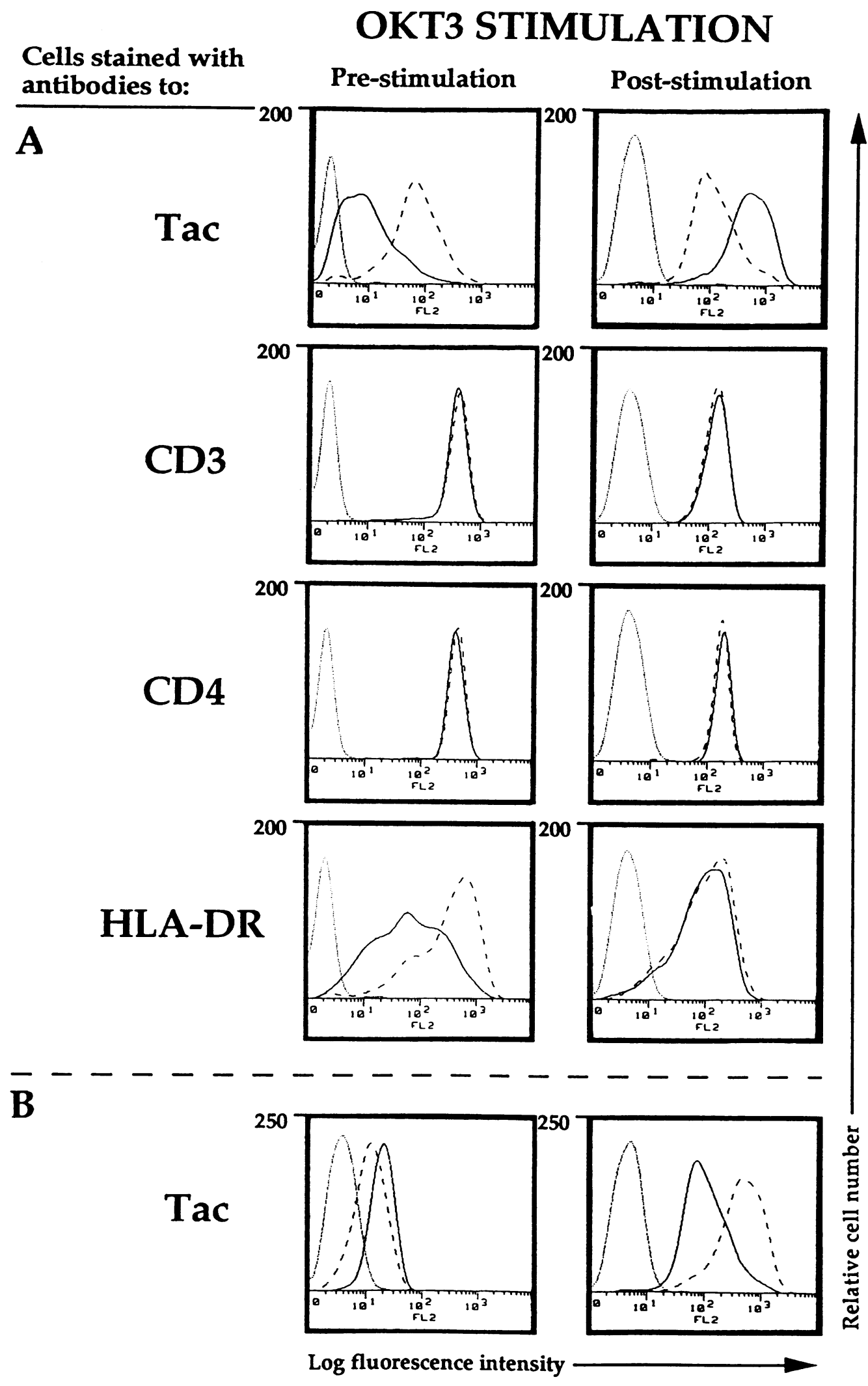

Figure 5. Effects of $(A)$ TNF and $(B)$ anti-TNF on surface antigen expression. Cells were cultured as described for Fig. 4 , prior to restimulation with optimal concentrations of immobilized OKT3. Cells were stained with the indicated $\mathrm{mAb}$ before and $48 \mathrm{~h}$ after OKT3 stimulation. The lower figure $(B)$ represents a separate experiment in which the effects of prolonged anti-TNF pretreatment on Tac expression following OKT3 stimulation is illustrated. Histogram plots represent cells stained with: $\cdots \cdots$ isotype matched control $\mathrm{mAb}$; - specific $\mathrm{mAb}$ to surface antigen (medium treated cells); - - specific $\mathrm{mAb}$ to surface antigen (TNF, Fig. 5 A; anti-TNF, Fig. $5 B$; treated cells).

levels of TNF-R and accordingly respond poorly to TNF in the absence of costimulatory factors (32). Even after activation, TNF exhibits only moderate comitogenic activity on $\mathrm{T}$ cells when compared to other monokines such as IL-1 (2). Recently, our studies demonstrating that activated synovial $\mathrm{T}$ lymphocytes express high levels of TNF-R (22) prompted a more thorough 


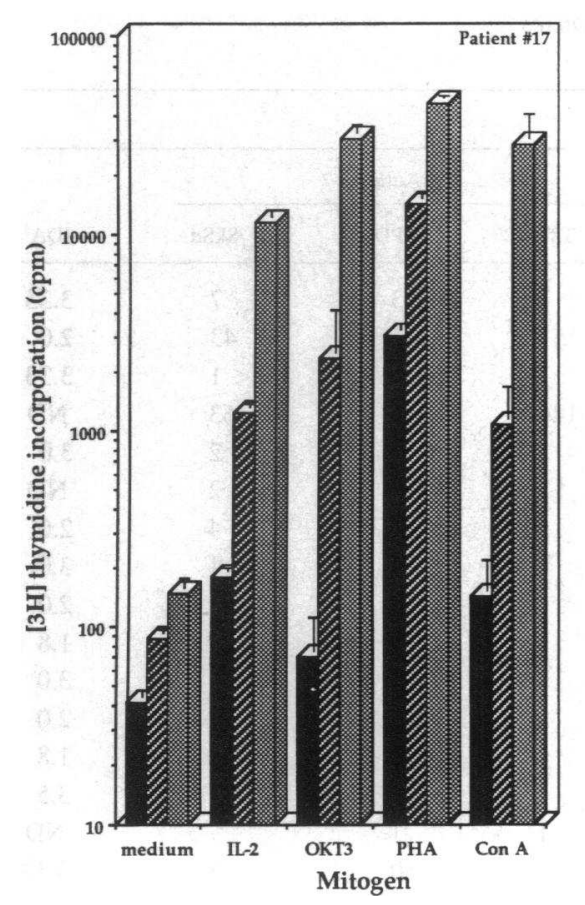

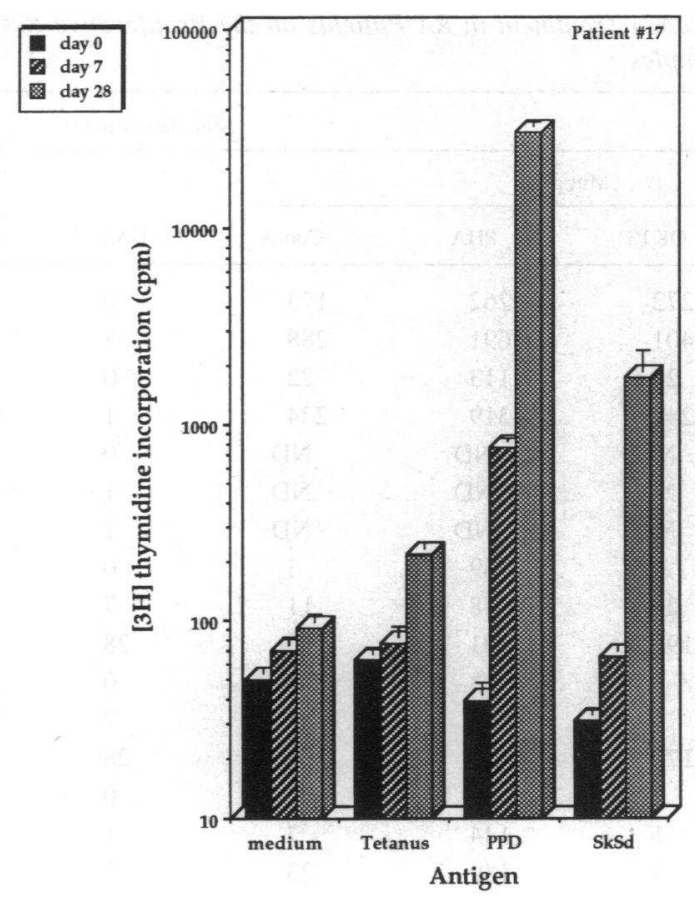

Figure 6. Anti-TNF treatment in RA patients restores the proliferative responses of PBMC to mitogens and soluble antigens. Serial unfractionated PBMC from RA patient 17 before (day 0) and after (days 7 and 28) anti-TNF treatment were cultured at $10^{5}$ cells per well with optimal concentrations of mitogens and soluble antigens as indicated in Table III. Results are expressed as mean cpm of triplicate cultures \pm SEM. Differences between day 0 and peak stimulation indices for all stimuli were statistically significant $(P$ $<0.03$ ). investigation of TNF effects on T cells. Since the beneficial effects of neutralizing TNF in RA patients suggested that TNF expression persists in vivo for prolonged periods (27), an evaluation of the chronic effects of TNF seemed clinically relevant.

We chose to study antigen-specific $T$ cell clones from healthy individuals, since the specificity of antigen responses in the joints of RA patients is not known. Using this in vitro model, our investigations revealed several interesting and unexpected findings. Firstly, chronic TNF exposure resulted in significant dose- and time-dependent reductions in responses of $T$ cells when stimulated subsequently through the TCR/CD3 complex, but not through the IL-2R. Secondly, under these conditions TNF caused a significant reduction in lymphokine production. Thirdly, stimulation of TNF-treated $\mathrm{T}$ cells led to suboptimal expression of Tac following activation. Finally, although concentrations of exogenous TNF required to induce suppressive effects were high ( $>10 \mathrm{ng} / \mathrm{ml}$ ), levels of endogenous TNF expressed by chronically activated $\mathrm{T}$ cell clones either in soluble or membrane form were sufficient to exert similar suppressive effects in culture, since prolonged TNF blockade with $\mathrm{mAb}$ in vitro enhanced both proliferative responses and lymphokine production. These properties would appear not to be a characteristic exclusive to TNF. Thus, we have begun to screen the effects of other cytokines for their effects on antigenspecific responses and lymphokine production; preliminary data suggest that chronic exposure to IL-1, but not to IL-6, can impair TCR-specific responses (A. Cope, unpublished data). Direct comparisons of the relative potency of TNF and IL-1 on a molar basis are in progress. On the other hand, equimolar concentrations of lymphotoxin (LT), which binds to the same receptors as TNF, induced less potent suppression of antigenspecific responses and lymphokine production compared with TNF-treated cultures. In this regard, LT has been shown to be less biologically active in several in vitro biological systems (42), with distinct activities from those of TNF (43). The reasons for these differences remain obscure.
There is an extensive literature documenting the potentiating effects of TNF in immune responses in vivo. This is particularly well illustrated in anti-tumor cell responses (44), as well as in animal models of allograft rejection (45), graft-versus-host disease (46), antilisterial immunity (47) and granuloma formation in BCG immunized mice (48). More recently, studies have demonstrated that anti-TNF, when administered to mice at the time of priming with antigen, interferes with the generation of both CD4 class II-restricted T cells mediating contact sensitivity, and CD8 class I-restricted anti-hapten cytotoxic T lymphocyte responses (49). That there were no obvious changes in the lymphoid populations in anti-TNF-treated animals suggested a functional effect of blocking TNF on cell-mediated immunity, rather than a direct lytic effect of antibody. Until now, there have been no detailed studies investigating the suppressive effects of TNF on human cells, although there is a report that TNF can suppress immune functions in mice. Thus, repeatedly injecting C57BL/6 mice with TNF over an 8-wk period induced lymphocytopenia, suppressed the proliferative responses of splenocytes to Con A, PHA, and LPS, inhibited cytotoxicity against allogeneic targets, and delayed type hypersensitivity reactivity, and completely abolished NK cell activity, while no effects on humoral immunity could be detected (50). A defect in accessory cell function rather than a direct effect on $\mathrm{T}$ cells was considered the likely mechanism, possibly resulting from the enhanced production of PGE2 induced by TNF. In contrast to these studies, our data demonstrated a direct effect of TNF on $\mathrm{T}$ cells, since we observed suppressive effects in vitro in the absence of antigen presenting cells. Furthermore, the suppressive effects of TNF were not cytostatic, and were equally potent in the presence of cyclooxygenase inhibitors.

Although a direct comparison between animal studies and those of our own are difficult, kinetic analyses in vitro and in vivo revealed that optimal suppression by TNF takes several days to develop. This implies that TNF may exert its suppressive effects by modulating the production of secondary mediators 
Table III. The Effects of Anti-TNF (cA2) Treatment in RA Patients on the Proliferative Responses of Serial Unfractionated PBMC Samples

\begin{tabular}{|c|c|c|c|c|c|c|c|c|c|}
\hline \multirow[b]{3}{*}{ RA Patient No. } & \multicolumn{9}{|c|}{ Stimulation index } \\
\hline & \multicolumn{4}{|c|}{ Mitogens } & \multirow[b]{2}{*}{ DAY* } & \multicolumn{3}{|c|}{ Antigens } & \multirow[b]{2}{*}{ IDA } \\
\hline & IL-2 & OKT3 & PHA & Con A & & $\mathrm{TT}$ & PPD & SkSd & \\
\hline \multirow[t]{2}{*}{11} & 84 & 272 & 262 & 173 & 0 & 7 & 3 & 7 & 3.33 \\
\hline & 206 & 401 & 691 & 288 & 7 & 57 & 21 & 43 & 2.0 \\
\hline \multirow[t]{2}{*}{13} & 41 & 25 & 113 & 22 & 0 & 1 & 116 & $<1$ & 3.33 \\
\hline & 107 & 242 & 319 & 234 & 1 & 146 & 649 & 163 & ND \\
\hline \multirow[t]{3}{*}{15} & ND & ND & ND & ND & 0 & 1 & 2 & 2 & 3.0 \\
\hline & ND & ND & ND & ND & 1 & 2 & 10 & 2 & ND \\
\hline & ND & ND & ND & ND & 7 & 5 & 25 & 4 & 2.0 \\
\hline \multirow[t]{3}{*}{17 (optimal) $^{\S}$} & 4 & 2 & 69 & 3 & 0 & $<1$ & 4 & $<1$ & 3.0 \\
\hline & 13 & 24 & 148 & 11 & 7 & $<1$ & 7 & $<1$ & 2.0 \\
\hline & 74 & 195 & 291 & 183 & 28 & 1 & 157 & 9 & 1.8 \\
\hline \multirow[t]{3}{*}{ (suboptimal) } & 4 & 1 & 138 & $<1$ & 0 & 1 & $<1$ & 1 & 3.0 \\
\hline & 7 & 4 & 267 & $<1$ & 7 & 1 & 13 & 1 & 2.0 \\
\hline & 53 & 170 & 449 & 21 & 28 & 1 & 210 & 28 & 1.8 \\
\hline \multirow[t]{3}{*}{19} & 11 & 1 & 229 & 4 & 0 & 1 & 1 & 1 & 3.5 \\
\hline & 9 & 1 & 144 & 7 & 1 & 1 & 1 & 7 & ND \\
\hline & 40 & 3 & 149 & 23 & 7 & 4 & 50 & 8 & 3.33 \\
\hline \multirow[t]{3}{*}{20} & 2 & $<1$ & 4 & 1 & 0 & ND & ND & ND & 3.17 \\
\hline & 24 & 5 & 136 & 25 & 7 & ND & ND & ND & 1.67 \\
\hline & 12 & 2 & 47 & 5 & 21 & ND & ND & ND & 2.0 \\
\hline$P$ value ${ }^{\|}$ & $<0.04$ & $<0.04$ & $>0.05$ & $<0.04$ & & ND & $<0.04$ & $<0.04$ & \\
\hline
\end{tabular}

Cells were stimulated as described for Fig. 6. Results are expressed as stimulation indices. ND—not determined. $*$ DAY - days after commencing anti-TNF treatment; ${ }^{\ddagger}$ IDA - not determined for DAY $1 ;{ }^{\S}$ concentrations of mitogens and antigens used (optimal:suboptimal, as indicated) were as follows: IL-2 (20 ng/ml:5 ng/ml), OKT3 $(50 \mathrm{ng} / \mathrm{ml}: 10 \mathrm{ng} / \mathrm{ml})$, PHA $(4 \mu \mathrm{g} / \mathrm{ml}: 1 \mu \mathrm{g} / \mathrm{ml})$, Con A $(4 \mu \mathrm{g} / \mathrm{ml}: 0.5 \mu \mathrm{g} / \mathrm{ml})$, tetanus toxoid (1/100:1/5000), PPD (10 $\mu \mathrm{g} / \mathrm{ml}: 2.5 \mu \mathrm{g} / \mathrm{ml})$ and SkSd $(5 \mu \mathrm{g} / \mathrm{ml}: 1 \mu \mathrm{g} / \mathrm{ml}) ; \quad$ " statistically significant differences between day 0 and peak stimulation indices for mitogens and antigens are shown.

such as cytokines or cell surface receptors. Under these circumstances, changes in $\mathrm{T}$ cell function might take days to develop. Accordingly, our studies demonstrated that chronic TNF exposure impaired OKT3-induced lymphokine production. Levels of all lymphokines detectable were significantly reduced, suggesting a potent, but nevertheless nonselective effect. Of particular significance was the downregulation of OKT3-induced IL2 production by TNF treatment, a feature which together with impaired IL-2R expression, could provide one important mechanism for the impaired growth responses of these cells. While TNF and LT production were reduced to below detectable limits in one experiment, levels of IL-10 were undetectable in both experiments. This raises the intriguing possibility that impairment of $\mathrm{T}$ cell function by TNF could arise from more subtle alterations in the profile of lymphokines they produce, rather than the more striking differences reported for lymphokines expressed by CD4 T cells of the TH1 or TH2 subsets in mice (51). In our experiments, IL-2 and IFN $\gamma$ levels were reduced following TNF pretreatment, even though significant levels of these lymphokines were still detectable, whereas levels of IL10 , a cytokine with inhibitory properties (52), were undetectable. By contrast, IL-10 production was increased more than six- to sevenfold by neutralizing endogenous TNF production with anti-TNF mAb, while IL-2, and IFN $\gamma$ levels increased only twofold. In this way, chronic TNF expression could disturb a delicate balance between levels of immunoregulatory and stimulatory lymphokines. An alternative possibility is that other cytokines that have not been investigated in this study are preferentially induced. At present we have not excluded the possibility that TNF in long-term culture selectively upregulates the production of TGF $\beta$ by $\mathrm{T}$ cells, although there is no precedent for this on the basis of studies in short-term cell cultures (53). In this regard, experiments have been performed on IL-4 producing clones to examine the effects of chronic TNF on the production of this growth factor, a lymphokine with potent antiinflammatory properties on some cell types $(54,55)$. Chronic TNF exposure was also found to suppress IL-4 production (S. Cohen, L. Webb, unpublished data).

It should be emphasized that detailed in vitro studies of the anti-TNF chimeric mAb used in this study have demonstrated potent inhibitory effects on the proliferation of primary PBMC cultures stimulated with antigens such as tetanus toxoid (M. Dalesandro, Centocor, Inc., unpublished data), and suggest that the enhanced cellular responses observed in our experiments are not due to nonspecific stimulatory effects. By experimental design, anti-TNF mAb were not present in any of the cultures during our rechallenge experiments. It is of interest, however, that, by flow cytometric analysis, cA2 recognizes membraneassociated TNF on T cell clones (A. Cope, unpublished data). Since membrane TNF is capable of signaling TNF effects (56, 57 ), it is conceivable that this form of the molecule contributes to the suppressive effects induced by endogenously expressed 
TNF. If so, this provides a novel mechanism by which cA2 can regulate immune function in the absence of detectable levels of soluble TNF. Partly because it is difficult to quantitate, the contribution of membrane TNF to normal and inflammatory responses is very likely to be underestimated; a comparison of the capacity for different TNF inhibitors to neutralize the activity of surface ligand will help to define the relative contribution of membrane and soluble TNF in this and other biological systems.

Although there is abundant evidence that the immune function of patients with severe RA is not normal $(33,58,59)$, there is little consensus as to the mechanisms of this immune suppression. Thus, the proliferative responses of both PBMC and synovial mononuclear cells to mitogens, recall antigens, the mixed lymphocyte reaction and, in cases of severe RA, IL-2 are markedly impaired. Furthermore, treatment of immunosuppressed patients with anti-TNF antibody, which has potent immunosuppressive properties in vitro, presents the potential risk of further suppressing immune function. On the other hand, the in vitro data reported here suggested to us that blocking endogenous TNF might have the effect of restoring cellular immune functions, by releasing $\mathrm{T}$ cells of the suppressive effects of chronic TNF exposure in vivo. In order to address which of these effects predominate in vivo, we studied $\mathrm{T}$ cell receptor and mitogen-specific responses of unfractionated mononuclear cell populations from patients with longstanding active RA before and immediately after treatment with anti-TNF. Consistent with our in vitro data, anti-TNF treatment in patients enhanced the proliferative responses of PBMC to a panel of T cell mitogens and recall antigens (Fig. 6 and Table III). Furthermore, these changes, which were observed within days of commencing anti-TNF treatment, appeared to parallel the rapid improvements observed in disease activity, irrespective of whether changes in clinical indices were sustained or transient. At this time, we have no evidence that the clinical benefit seen is related to improvements in T cell immunity. One possibility is that TNF exerts its effects in vivo by impairing accessory cell function, although the finding that populations of synovial or peripheral blood accessory cells from RA patients are potent stimulators of autologous mixed lymphocyte reactions would argue against this (60). Another possibility relates to TNF and its role in cell trafficking (11), a process whose modulation could alter significantly the populations of cells within the peripheral blood compartment. For example, no changes in the proportion of $\mathrm{CD} 4+\mathrm{T}$ cells in PBMC have been noted following cA2 treatment, while small increases in the proportion of $\mathrm{CD} 45 \mathrm{RO}+$ "memory" $\mathrm{T}$ cells were observed in three patients evaluated (unpublished data). Clearly, studies are required to establish whether these increased responses reflect qualitative and/or quantitative effects of TNF on memory T cells in vivo. Further investigations of patients and animals will allow us to define precisely how the beneficial effects of anti-TNF on disease activity and immune function are interlinked. Nevertheless, our data support the hypothesis that chronic TNF exposure in vivo dampens cellular immune responses. More importantly from the clinical point of view, treatment of immunosuppressed patients with anti-TNF does not further suppress cellular immunity, but rather enhances these responses, restoring them towards normal. This finding may be of considerable practical importance in the treatment of diseases in which TNF blockade is beneficial to patients.

\section{Acknowledgments}

The authors thank Alice Long-Fox and Gail Harris for providing samples from RA patients treated with anti-TNF.

This work was supported by The Wellcome Trust, The Medical Research Council, The Arthritis and Rheumatism Council, The British Diabetic Association and Centocor Inc.

\section{References}

1. Beutler, B., and A. Cerami. 1989. The biology of cachectin/TNF- a primary mediator of the host response. Annu. Rev. Immunol. 7:625-655.

2. Yokota, S., T. Geppert, and P. Lipsky. 1988. Enhancement of antigen- and mitogen-induced human $\mathrm{T}$ lymphocyte proliferation by tumor necrosis factor- $\alpha$. J. Immunol. 140:531-536.

3. Kehrl, J. H., A. Miller, and A. S. Fauci. 1987. Effects of tumor necrosis factor alpha on mitogen-activated human B cells. J. Exp. Med. 166:786-791.

4. Ding, A., C. F. Nathan, and D. J. Stuehr. 1988. Release of reactive nitrogen intermediates and reactive oxygen intermediates from mouse peritoneal macrophages: comparison of activating cytokines and evidence for independent production. J. Immunol. 141:2407-2412.

5. Dayer, J.-M., B. Beutler, and A. Cerami. 1985. Cachectin/tumor necrosis factor stimulates collagenase and prostaglandin $\mathrm{E}_{2}$ production by human synovial cells and dermal fibroblasts. J. Exp. Med. 162:2163-2168.

6. Dinarello, C. A., J. G. Cannon, S. M. Wolff, H. A. Bernheim, B. Beutler, A. Cerami, I. S. Figari, M. A. Palladino Jr, and J. V. O’Connor. 1986. Tumor necrosis factor (cachectin) is an endogenous pyrogen and induces production of interleukin 1. J. Exp. Med. 163:1433-1450.

7. Turner, M., D. Chantry, G. Buchan, K. Barrett, and M. Feldmann. 1989. Regulation of expression of human IL-1 alpha and IL-1 beta genes. J. Immunol. 143:3556-3561.

8. Brouckaert, P., D. R. Spriggs, G. Demetri, D. W. Kufe, and W. Fiers. 1989. Circulating interleukin 6 during a continuous infusion of tumor necrosis factor and interferon $\gamma$. J. Exp. Med. 169:2257-2262.

9. Broudy, V. C., K. Kaushensky, G. M. Segal, J. M. Harlan, and J. W. Adamson. 1986. Tumor necrosis factor type $\alpha$ stimulates human endothelial cells to produce granulocyte-macrophage colony stimulating factor. Proc. Natl. Acad. Sci. USA. 83:7467-7471.

10. Munker, R., J. Gasson, M. Ogawa, and H. P. Koeffer. 1986. Recombinant TNF induces production of granulocyte-monocyte colony-stimulating factor. $\mathrm{Na}$ ture (Lond.) 323:79-82.

11. Pober, J. S., M. A. Gimbrone Jr., L. A. Lapierre, D. L. Medrick, W. Fiers, R. Rothlein, and T. A. Springer. 1986. Activation of human endothelium by lymphokines: overlapping patterns of antigenic modulation by interleukin 1, tumor necrosis factor and immune interferon. J. Immunol. 137:1893-1896.

12. Strieter, R. M., S. L. Kunkel, H. J. Showell, D. G. Remick, S. H. Phan, P. A. Ward, and R. M. Marks. 1989. Endothelial cell gene expression of a neutrophil chemotactic factor by TNF $\alpha$, LPS, and IL-1 $\beta$. Science (Wash. DC). 243:1467-1469.

13. Franciotta, D. M., L. M. E. Grimaldi, G. V. Martino, G. Piccolo, R. Bergamaschi, A. Citterio, and G. V. Melzi-d'Eril. 1989. Tumor necrosis factor in serum and cerebrospinal fluid of patients with multiple sclerosis. Ann. Neurol. 26:787-789.

14. Murch, S. H., V. A. Lamkin, M. O. Savage, J. A. Walker-Smith, and T. T. MacDonald. 1991. Serum concentrations of tumor necrosis factor alpha in childhood chronic inflammatory bowel disease. Gut. 32:913-917.

15. Whittle, H., J. Brown, K. Marsh, M. Blackman, O. Jobe, and F. Shanton 1990. The effects of Plasmodium falciparum malaria on immune control of B lymphocytes in Gambian children. Clin. Exp. Immunol. 80:213-218.

16. Pisa, P., M. Gennene, O. Soder, T. Ottenhoff, M. Hansson, and R. Kiessling. 1990. Serum tumor necrosis factor levels and disease dissemination in leprosy and leishmaniasis. J. Infect. Dis. 161:988-991.

17. Oliff, A., D. Defeo-Jones, M. Boyet, D. Martinez, D. Kiefer, G. Vuocolo, A. Wolfe, and S. H. Socher. 1987. Tumors secreting human TNF/cachectin induce cachexia in mice. Cell. 50:555-563.

18. Tracey, K. J., H. Wei, K. R. Manogue, Y. Fong, D. G. Hesse, H. T. Nguyen, G. C. Kuo, B. Beutler, R. S. Cotran, A. Cerami and S. Lowry. 1988 Cachectin/tumor necrosis factor induces cachexia, anemia, and inflammation. $J$. Exp. Med. 167:1211-1227.

19. Feldmann, M., F. M. Brennan, D. Chantry, C. Haworth, M. Turner, E. Abney, G. Buchan, K. Barrett, D. Barkley, A. Chu, M. Field, and R. N. Maini. 1990. Cytokine production in the rheumatoid joint: implications for treatment. Ann. Rheum. Dis. 49:480-486.

20. Brennan, F. M., D. Chantry, A. M. Jackson, R. N. Maini, and M. Feldmann. 1989. Cytokine production in culture by cells isolated from the synovial membrane. In T-cell Activation in Health and Disease. M. Feldmann, R. N. Maini, and J. Woody, editors. Academic Press, London, UK. 177-186. 
21. Buchan, G., K. Barrett, M. Turner, D. Chantry, R. N. Maini, and M. Feldmann. 1988. Interleukin-1 and tumour necrosis factor mRNA expression in rheumatoid arthritis: prolonged production of IL-1 $\alpha$. Clin. Exp. Immunol. 73:449455.

22. Brennan, F. M., D. L. Gibbons, T. Mitchell, A. P. Cope, R. N. Maini, and M. Feldmann. 1992. Enhanced expression of tumour necrosis factor receptor mRNA and protein in mononuclear cells isolated from rheumatoid arthritis synovial joints. Eur. J. Immunol. 22:1907-1912.

23. Brennan, F. M., D. Chantry, A. Jackson, R. N. Maini, and M. Feldmann. 1989. Inhibitory effects of TNF $\alpha$ antibodies on synovial cell interleukin-1 production in rheumatoid arthritis. Lancet. ii:244-247.

24. Haworth, C., F. M. Brennan, D. Chantry, M. Turner, R. N. Maini, and M. Feldmann. 1991. Expression of granulocyte-macrophage colony-stimulating factor (GM-CSF) in rheumatoid arthritis: regulation by tumour necrosis factora. Eur. J. Immunol. 21:2575-2579.

25. Keffer, J., L. Probert, H. Cazlaris, S. Georgopoulos, E. Kaslaris, D. Kioussis, and G. Kollias. 1991. Transgenic mice expressing human tumour necrosis factor: a predictive genetic model of arthritis. EMBO (Eur. Mol. Biol. Organ.) J. 10:4025-4031.

26. Williams, R. O., M. Feldmann, and R. N. Maini. 1992. Anti-tumour necrosis factor ameliorates joint disease in murine collagen-induced arthritis. Proc. Natl. Acad. Sci. USA. 89:9784-9788.

27. Elliott, M. J., R. N. Maini, M. Feldmann, A. Long-Fox, P. Charles, P. Katsikis, F. M. Brennan, J. Walker, H. Bijl, J. Ghrayeb, and J. N. Woody. 1993. Treatment of rheumatoid arthritis with chimaeric antibodies to tumour necrosis factor- $\alpha$. Arthritis Rheum. 36:1681-1690.

28. Van Boxel, J. A., and S. A. Paget. 1975. Predominantly T cell infiltrate in rheumatoid synovial membranes. N. Engl. J. Med. 293:517-520.

29. Morimoto, C., P. L. Romain, D. A. Fox, P. Anderson, M. DiMaggio, H. Levine, and S. F. Schlossman. 1988. Abnormalities of CD4+ T lymphocyte subsets in inflammatory rheumatic disease. Am. J. Med. 84:817-825.

30. Cush, J. J., and P. E. Lipsky. 1988. Phenotypic analysis of synovial tissue and peripheral blood lymphocytes isolated from patients with rheumatoid arthritis. Arthritis Rheum. 31:1230-1238.

31. Turner, M., M. Londei, and M. Feldmann. 1987. Human T cells from autoimmune and normal individuals can produce tumour necrosis factor. Eur. $J$. Immunol. 17:1807-1814.

32. Scheurich, P., B. Thoma, U. Ucer, and K. Pfizenmaier. 1987. Immunoregulatory activity of recombinant human tumor necrosis factor (TNF)- $\alpha$ : induction of TNF receptors on human T cells and TNF- $\alpha$-mediated enhancement of T cell responses. J. Immunol. 138:1786-1790.

33. Silverman, H. A., J. S. Johnson, J. H. Vaughan, and J. C. McGlamory. 1976. Altered lymphocyte reactivity in rheumatoid arthritis. Arthritis Rheum. 19:509-515.

34. Firestein, G. S., W.-D. Xu, K. Townsend, D. Broide, J. Alvaro-Garcia, A Glasebrook, and N. J. Zvaifler. 1988. Cytokines in chronic inflammatory arthritis I. Failure to detect $T$ cell lymphokines (interleukin 2 and interleukin 3 ) and presence of macrophage colony-stimulating factor (CSF-1) and a novel mast cell growth factor in rheumatoid synovitis. J. Exp. Med. 168:1573-1586.

35. Firestein, G. S., and N. J. Zvaifler. 1987. Peripheral blood and synovial fluid monocyte activation in inflammatory arthritis II. IFN- $\gamma$ is not the primary macrophage activating factor. Arthritis Rheum. 30:864-871.

36. Londei, M., G. F. Bottazzo, and M. Feldmann. 1985. Human T-cell clones from autoimmune thyroid glands: specific recognition of autologous thyroid cells Science (Wash. DC). 288:85-89.

37. Ho, S. N., R. T. Abraham, S. Gillis, and D. J. Mckeon. 1987. Differential bioassay of interleukin 2 and interleukin 4. J. Immunol. Methods. 98:99-104.

38. Arnett, F. C., S. M. Edworthy, D. A. Bloch, D. J. McShane, J. F. Fries, N. S. Cooper, L. A. Healey, S. R. Kaplan, M. H. Liang, T. A. Medsger, D. M Mitchell, D. H. Neustadt, R. S. Pinals, J. G. Schaller, J. T. Sharp, R. L. Wilder, and G. C. Hunder. 1988. The American Rheumatism Association 1987 revised criteria for the classification of rheumatoid arthritis. Arthritis Rheum. 31:315324.

39. Mallya, R. K., and B. E. W. Mace. 1981. The assessment of disease activity in rheumatoid arthritis using a multivariate analysis. Rheumatol. Rehabil. 20:14-17.

40. Pfizenmaier, K., P. Scheurich, C. Schluter, and M. Kronke. 1987. Tumor necrosis factor enhances HLA-A, B, C and HLA-DR gene expression in human tumor cells. J. Immunol. 138:975-980.

41. Imamura, K., D. Spriggs, and D. Kufe. 1987. Expression of tumor necrosis factor receptors on human monocytes and internalisation of receptor bound ligand. J. Immunol. 139:2989-2992.

42. Kircheis, R., J. Milleck, V. G. Korobko, L. N. Shingarova, and H. E. Schmidt. 1992. Differences in the biological activity of TNF $\alpha$ and TNF $\beta$ correlates with their different abilities for binding to the target cells. Cytokine Netw. $3: 381-390$

43. Porter, A. G. 1990. Human tumour necrosis factors- $\alpha$ and $\beta$ : differences in their structure, expression and biological properties. FEMS (Fed. Eur. Microbiol. Soc.) Microbiol. Immunol. 64:193-199.

44. Talmadge, J. E., H. Phillips, M. Schneider, T. Rowe, R. Pennington, O. Bowersox, and B. Lenz. 1988. Immunomodulatory properties of recombinan murine and human tumour necrosis factor. Cancer Res. 48:544-550.

45. Imagawa, D. K., J. M. Millis, K. M. Olthoff, P. Seu, R. A. Dempsey, J. Hart, P. I. Terasaki, E. M. Wasef, and R. W. Busutil. 1990. The role for tumor necrosis factor in allograft rejection II. Evidence that antibody therapy against human tumor necrosis factor-alpha and lymphotoxin enhances cardiac allograft survival in rats. Transplantation (Baltimore). 50:189-93.

46. Piguet, P.-F., G. E. Grau, B. Allet, and P. Vassalli. 1987. Tumor necrosis factor/cachectin is an effector of skin and gut lesions of the acute phase of graft vs. host disease. J. Exp. Med. 166:1280-1289.

47. Bancroft, G. J., K. C. Sheehan, R. D. Schreiber, and E. R. Unanue. 1989. Tumor necrosis factor is involved in the $T$ cell-independent pathway of macrophage activation in scid mice. J. Immunol. 143:127-130.

48. Kindler, V., A. P. Sappino, G. E. Grau, P. F. Piguet, and P. Vassalli. 1989. The inducing role of tumor necrosis factor in the development of bactericidal granulomas during BCG infection. Cell. 56:731-740.

49. Bromberg, J. S., K. D. Chavin, and S. L. Kunkel. 1992. Anti-tumo necrosis factor antibodies suppress cell-mediated immunity in vivo. J. Immunol. 148:3412-3417.

50. Gordon, C., and D. Wofsy. 1990. Effects of recombinant murine tumor necrosis factor- $\alpha$ on immune function. J. Immunol. 144:1753-1758.

51. Mosmann, T. R., and R. L. Coffman. 1989. TH1 and TH2 cells: Differen patterns of lymphokine secretion lead to different functional properties. Annu. Rev. Immunol. 7:145-173.

52. de Waal Malefyt, R., J. Abrams, B. Bennett, C. G. Figdor, and J. E. de Vries. 1991. Interleukin 10 (IL-10) inhibits cytokine synthesis by human monocytes: an autoregulatory role by IL-10 produced by monocytes. J. Exp. Med. 174:1209-1220.

53. Chantry, D., M. Turner, E. Abney, and M. Feldmann. 1989. Modulation of cytokine production by transforming growth factor- $\beta$. J. Immunol. 142:42954300 .

54. Hart, P. H., G. F. Vitti, D. R. Burgess, G. A. Whitty, D. S. Piccoli, and J. H. Hamilton. 1989. Potential anti-inflammatory effects of interleukin-4 Suppression of human monocyte tumor necorsis factor $\alpha$, interleukin-1, and prostaglandin E2. Proc. Natl. Acad. Sci. USA. 86:3803-3807.

55. Cope, A. P., D. L. Gibbons, D. Aderka, B. M. J. Foxwell, D. Wallach, R. N. Maini, M. Feldmann, and F. M. Brennan. 1993. Differential regulation of tumour necrosis factor receptors (TNF-R) by IL-4; upregulation of p55 and p75 TNF-R on synovial joint mononuclear cells. Cytokine. 5:205-212.

56. Kriegler, M., C. Perez, K. Defay, I. Albert, and S. Lu. 1988. A nove form of TNF/cachectin is a cell surface cytotoxic transmembrane protein: ramifications for the complex physiology of TNF. Cell. 53:45-53.

57. Kinkhabwala, M., P. Sehajpal, E. Skolnick, D. Smith, V. K. Sharma, H Vlassara, and A. Cerami. 1990. A novel addition to the T cell repertory. Cell surface expression of tumor necrosis factor/cachectin by activated normal human T cells. J. Exp. Med. 171:941-946.

58. Emery, P., G. S. Panayi, and A. M. E. Nouri. 1984. Interleukin-2 reverses deficient cell-mediated immune responses in rheumatoid arthritis. Clin. Exp. Immunol. 57:123-129.

59. Haraoui, B., R. L. Wilder, D. G. Malone, J. B. Allen, I. M. Katona, and S. M. Wahl. 1984. Immune function in severe, active rheumatoid arthritis: A relationship between peripheral blood mononuclear cell proliferation to soluble antigens and mononuclear cell subset profiles. J. Immunol. 133:697-701.

60. Silver, R. M., D. Redelman, and N. J. Zvaifler. 1983. Studies of rheumatoid synovial fluid lymphocytes. II. A comparison of their behaviour with blood mononuclear cells in the mixed lymphocyte reaction and responses to TCGF. Clin. Immunol. Immunopathol. 27:15-27. 